\title{
Prevalence and Correlates of Prediabetes and Diabetes Results-I: A Screening Plan in a Selected Military Community in Central Saudi Arabia
}

\author{
Raouf M. Afifi'1,2*, Ashraf E. Saad ${ }^{3}$, Ahmed Al Shehri ${ }^{4}$ \\ ${ }^{1}$ Community Health Research Institute, International Management-Health Services, Indianapolis, IN, USA \\ ${ }^{2}$ Community Medicine Program, Armed Forces Hospitals, Taif, KSA \\ ${ }^{3}$ Preventive Medicine Department, Armed Forces Hospital at Wadi Al-Dawasir, Riyadh, KSA \\ ${ }^{4}$ Family Medicine Department, Armed Forces Hospital at Wadi Al-Dawasir, Riyadh, KSA \\ Email: ${ }^{\star}$ raoufafifi@itm-hs.org, ${ }^{\star}$ raoufafifi43@gmail.com
}

How to cite this paper: Afifi, R.M., Saad, A.E. and Al Shehri, A. (2017) Prevalence and Correlates of Prediabetes and Diabetes Results-I: A Screening Plan in a Selected Military Community in Central Saudi Arabia. Journal of Diabetes Mellitus, 7, 12-30. https://doi.org/10.4236/jdm.2017.71002

Received: December 3, 2016

Accepted: January 16, 2017

Published: January 19, 2017

Copyright $\odot 2017$ by authors and Scientific Research Publishing Inc. This work is licensed under the Creative Commons Attribution International License (CC BY 4.0).

http://creativecommons.org/licenses/by/4.0/

\section{Abstract}

Background: Diabetes is a chronic disease of a genetic and environmental background. If it is not diagnosed and controlled early, it can have devastating complications. Aim: Measure and analyze the prevalence and risks of prediabetes and diabetes among recruits enlisted in the Wadi Al-Dawasir (WD) military zone, central Saudi Arabia. The influence of some demographic criteria, weight, and blood pressure upon blood glucose level would be evaluated. Methods: A cross sectional design was utilized, whereas predesigned questionnaire and clinical interview were used to screen the study population. Results: The participants' median age was 33.7 (IQR 11.9), mean body mass index (BMI) was $27.6 \pm 5.4 \mathrm{~kg} / \mathrm{m}^{2}$. Out of 531 recruits screened, almost two-thirds were either overweight $(34.7 \%)$ or obese $(29.9 \%)$. The mean waist circumference (WC) was $94.7 \pm 13.3 \mathrm{~cm}$; and $27.9 \%$ had central obesity (WC $\geq 102$ $\mathrm{cm}$ ). Random plasma glucose (RPG) median accounted $106 \mathrm{mg} / \mathrm{dl}$ (IQR 21). The participants' RPG levels significantly increased by age $(U=19697.0)$, by BMI $[H(\mathrm{df} 5)=59.6]$, and by WC $(U=25,670.5),(p<0.0001$, all tests $)$. Likewise, systolic blood pressure and RPG levels were significantly correlated $[$ rho $(\mathrm{df} 503)=0.241, p<0.0001]$. Furthermore, $29(5.6 \%)$ subjects had RPG 2200mg\%: 23 (4.3\%) known diabetic (uncontrolled) and 6 (1.3\%) undiagnosed (pre-diabetes). Known diabetics tended to record higher RPG values than non-diabetics $(U 3515, p<0.0001)$. Weight did not influence the development of overt diabetes or prediabetes conditions. Yet known diabetics were prone to recording higher BMI ( $>25$ to $\geq 40 \mathrm{~kg} / \mathrm{m}^{2}$ ) more than normal subjects [46 (87\%) vs. $5(0.9 \%)],\left[\chi^{2}(\mathrm{df} 5)=18.8, p<0.0001\right]$. Conclusions: Prediabetes and uncontrolled diabetes are relatively prevalent among Saudi recruits' 
community. An insufficient influence of obesity for developing diabetes symptoms in the study population may well be attributed to time factor separating the two variables. A preventive approach to revert the predisposition of prediabetes in WD recruits population is quite promising.

\section{Keywords}

Pre-Diabetes, Diabetes, Wadi Al-Dawasir, Saudi Arabia

\section{Introduction}

Diabetes is one of the five leading causes of death worldwide. According to the International Diabetes Federation (IDF), in 2015 some 415 million people worldwide, or $8.8 \%$ of adults aged 20 - 79, were estimated to have diabetes; including 193 million undiagnosed [1], and with nearly equal rates in both women and men [2]. In type 2 diabetes, a metabolic disorder in the context of insulin resistance and relative insulin deficiency leads to the elevated blood glucose level [3]. An increase of exercise and dietary modification is part of the management of type 2 DM [4]. A combination of lifestyle and genetic factors plays a strong role in the development of this disease. In one study, those who had high levels of physical activity (PA), a healthy diet (one high in fiber, with a high polyunsaturated to saturated fat ratio, and a lower mean glycemic index), did not smoke, and consumed alcohol in moderation had an $82 \%$ lower rate of diabetes [5]. When a normal weight was included, the rate was $89 \%$ lower. While about 55 percent of type 2 diabetes patients are obese at diagnosis [6] [7], chronic obesity leads to increased insulin resistance that can develop into type 2 diabetes, most likely because adipose tissue, (especially the intra-abdominal) is a source of hormones and cytokines. Clinically, obesity can be expressed in terms of body mass index (BMI), waist circumference (WC), and waist-to-hip ratio. The three measurements have been shown to be associated with type 2 diabetes [8]. The central obesity (approximated by WC) with the diabetogenic substances generated is often perceived as being more informative; yet because of their high correlation, BMI and WC are unlikely to yield different answers [8]. In a retrospective study on the use of WC to predict insulin resistance on a sample of 2746 healthy volunteers, WC $<100 \mathrm{~cm}$ excluded individuals (both sexes) from the risk of being insulin resistant [9]. That in mind, WC can still replace BMI, waist-to hip ratio, and other measures of total body fat as a predictor of insulin resistance in human body. On the other hand, type 2 diabetes may cause obesity as an effect of the changes in metabolism and other deranged cell behavior attendant on insulin resistance [10].

Risk factors for DM and chronic hyperglycemic conditions. Medical conditions, such as hypertension (HTN) and elevated cholesterol (combined hyperlipidemia) [11] can potentially give rise to, or exacerbate, type 2 diabetes. Additional factors found to increase the risk of type 2 diabetes include aging [12] and 
a less active lifestyle [13]. Important, too, is that environmental factors together with a genetic predisposition, plays a pivotal role in the development of type 2 diabetes. For instance, a positive correlation has been found between the concentration in the urine of bisphenol-A, a plastic constituent, and the incidence of type 2 diabetes [14]. The combined environmental-genetic influence on developing type $2 \mathrm{DM}$ can be evidenced, e.g., from the adoption of epidemiological pattern of type 2 diabetes in those who have moved to a different environment as compared to the same genetic pool that have not, e.g., immigrants to Western countries, as compared to lower incidence countries of origins [15]. Such developments can also be found in environments which have had a recent increase in social wealth, increasingly common throughout Asia, including the oil countries. Ethnicity-wise, too, some type-2 diabetes groups are affected differently, probably due to unique risk factors. For example, African Americans have a 12-fold greater prevalence than black natives of Africa [16]. Overall, diabetes remains to be an expanding global health crisis that the world prevalence of diabetes, age 20 79 , was $6.4 \%$, affecting 285 million in 2010, and expectedly increasing to $7.7 \%$ (439 million) by 2030. Between 2010 and 2030, there will be a $69 \%$ increase in numbers of adults with diabetes in developing countries and a $20 \%$ increase in developed countries [17].

Risks and burden of diabetes in the Kingdom of Saudi Arabia (KSA): In the Kingdom of Saudi Arabia (KSA), the major epidemiologic features of diabetes are not departure from that widely seen worldwide. Like other oil-rich countries, leaving behind the physically demanding life of the desert for air-conditioned comfort, servants, fast food and meat based dishes replacing fiber rich foods, KSA struggles with obesity and diabetes. About $60 \%$ of the Saudi population is now overweight (BMI 25 - 30, all ages); the older the age the greater BMI [18]. In turn, BMI can be a sedentary lifestyle to worsen by age. Parallelly, the prevalence of DM among adult Saudis has reached 23.7\%, a proportion that is one of the highest in the world [19] [20]. The burden of diabetes upon the Saudi society continues to be on the rise; the more newly diagnosed diabetes the more population at risk of developing heart disease, stroke, HTN, kidney disease, nervous system disease, amputations, visual impairment, and dental disease [21]. Knowledge and awareness about diabetes, its risk factors, complications and management are important aspects for better control and better quality of life (QOL) [22], especially in places where diabetes and related determinants, as in $\mathrm{KSA}$, are in escalation. The issue is by the time people are diagnosed with diabetes, they frequently have developed severe complications, e.g., retinopathy (a microangiopathic process), or ischemic heart disease (IHD) (a macroangiopathic process). Thereby, the fact that certain risks, i.e., lifestyle, medical and environmental factors may precipitate diabetes, especially in the genetically predisposed, and that diabetes itself leads to consequences, some of which are underlying triggers, warrant early intervention to interrupt the circle, and hence control the diabetes problem in the community. For instance, HTN can lead to and make worse many complications of diabetes, including diabetic eye disease and kidney 
disease. Most people with diabetes develop high blood pressure during their life, mostly because of subsequent atherosclerotic changes. High blood pressure (BP), in turn, if not treated, can lead to further blood vessel damage and worsening angiopathic-related complications of diabetes, as in aforementioned. Within the context of secondary prevention, screening can be an intervention of first choice. Internationally, the same concern that almost one-third of people with type 2 diabetes may be undiagnosed is distressing to health policy planners [23]. Because blood glucose can rise to diabetic levels with little or nothing in the way of symptoms, early detection of diabetes at the national level would lead to measures to reduce the risk of heart disease, e.g., the use of statins to lower cholesterol, the reduction of blood glucose levels initially by diet and exercise, supplemented with hypoglycemic drugs, as necessary, and the likes [24].

Screening and handling the diabetes problem: Generally, screening in asymptomatic populations is appropriate when seven conditions are met: 1 ) the disease represents an important health problem that imposes a significant burden on the population, 2) the natural history of the disease is understood, 3) there is a recognizable preclinical stage during which the disease can be diagnosed, 4) reliable tests are available that can detect such preclinical stage, 5) treatment after early detection yields benefits superior to those obtained when treatment is delayed, 6) the costs of treatment are reasonable and are balanced in relation to health expenditures, and resources are available to treat newly diagnosed cases, and 7) screening will be a systematic ongoing process and not merely an isolated one-time effort [25]. For diabetes, conditions 1 - 4 are met. The effectiveness of screening also depends on the setting in which it is performed. Should the positively screened fail to obtain appropriate follow-up care or should appropriate retesting for those screened negative is not ensured, the effectiveness of screening may be compromised [26]. Thereby, the World Health Organization (WHO) recommends diabetes screening in some risk groups, including older age categories [27]. The US Preventive Services Task Force recommend diabetes screening in adults without symptoms and whose BP is greater than $135 / 80 \mathrm{mmHg}$ [28].

Screening tools: Generally, a variety of methods, including risk assessment questionnaires, and analyses based on the measurement of plasma glucose concentration performed on venous samples with enzymatic assay techniques [25], for prediabetes screening are in use, e.g., pencil and paper tests, such as the American Diabetes Association (ADA) risk test, may be useful for educational purposes but do not perform well as stand-alone tests. Prediabetes screening analyses include, but are not limited to, fasting plasma glucose (FPG); the 75-g oral glucose tolerance test (OGTT), and casual (random) plasma glucose (RPG) level [29]. Further, various cutoffs at different healthcare and community settings, including the portable capillary blood assessments, are used. Importantly, the presence of a positive prediabetes state indicates a high risk for developing DM [29]. The current work was based on the hypothesis that in view of the alarming figures of diabetes in Saudi Arabia, priority groups and well defined communities e.g., servicemen and recruits in WD may benefit from diabetes 
screening, and hence be protected from the complications of diabetes through a systematic screening to help pursue serving flag with well-maintained health and physical fitness.

\section{Methodology}

Wadi Al Dawasir (WD) is a town in Dawasir valley in Saudi Najd desert. It lies within the jurisdiction of the Riyadh region, $613 \mathrm{~km}$ south of Capital Riyadh. According to 2010 Census (http://www.stats.gov.sa/en), WD municipality has 68,201 populations. The headquarter (HQ) of WD military district, supported by the preventive medicine and family medicine departments at Armed Force Hospital at WD (AFHWD), has approved a screening plan to identify the epidemiology of a multitude of chronic disease conditions among recruits. The plan was part of a broader "community diagnosis" project to maintain and improve the health status of WD military, and civilian, community, adopting screening and prevention as most favorable and cost-effective approach. In the first phase of the plan (started 2014), the prevalence of some chronic diseases of particular interest to WD populations, including hypothyroidism, cardiovascular disease (CVD), bronchial asthma (BA), renal disease, liver disease, sickle cell disease (SCD), and malignancy was studied. In the current phase, the prevalence of prediabetes/diabetes, pre-HTN/HTN, obesity, with some associated health trends would be assessed. The dataset in this research was focused on RPG status and risk factors hypothesized to be related to the development of prediabetes/diabetes, namely, age, body mass, central obesity, BP. Major Corps and satellite military units, including AFHWD personnel, which comprise the study population, were visited.

Data collection and study population: A validated Arabic-language instrument modified from the "Behavioral Risk Factor Survey" (BRFS) questionnaire [30] [31] was employed to cross-section the study population. All recruits enlisted in WD military zone were invited to the study. All were males. Otherwise, no individuals would be excluded due to certain demographic, health, or lifestyle criteria. Accordingly all subjects would be included. The questionnaire consists of 44 "items" (variables) in five scales: 1) demographic criteria, e.g., age, income, marital status, children, education, 2) risk factors, e.g., tobacco use, 3) lifestyle, e.g., BMI, PA, 4) chronic diseases, e.g., perceived health status, HTN, DM, and 5) screening attitude, e.g., lipid profile and colonoscopy screening (for at-risk population). The questionnaire takes 25 - 30 minutes to complete. Official approvals from HQ in charge and required local permissions from medical services department (MSD) to commence screening were obtained. Also a clearance from AFHWD Management was granted. Returned questionnaires reporting valid answers on $\geq 80 \%$ of the items would be admitted to the study. In preparation for the study, a pilot administration was conducted to assess the questionnaire's test-retest reliability. Thirty recruits and officers were given the questionnaire to respond to (response-a). The same questionnaire was re-administered by the same group one week later (response-b). A panel of juries was selected to judge 
the responses; test-retest reliability calculated to assess the temporal stability of the utilized utilizing correlation techniques. An acceptable-strong reliability evidence for the questionnaire's items was found: reliability alphas 0.83 for health risks, 0.72 for lifestyle, 0.93 for chronic diseases, and 0.901 for screening tests scales. On the field visits, recruit in each unit and location were addressed of the plan aim and objectives and furthered with a health education session about healthy lifestyle, chronic disease risks and preventive measures to maintain and improve health. However participants were informed that enrolment in the screening plan was voluntary, and that any participant could opt to withdraw any time during the study without any negative implications on their health benefits or professional entitlements. Confidentiality of collected information and clinical data had been assured, and a signed consent to take part in the screening plan was obtained participants.

Upon completion of the questionnaire, each surveyee was invited to a clinical interview. No questionnaire respondent refused the interview. A proforma was designed to endorse and follow up collected clinical data. The following physiological measurements were obtained: 1) weight, measured to the nearest of 0.1 $\mathrm{kg}$ on physician balance beam scales, with the subject wearing light clothes and with no shoes; all scales were identical and calibrated with a standard InterASIA protocol [32], 2) height, measured without shoes to the nearest of $0.1 \mathrm{~cm}$ using a stadiometer, where BMI $\left(\mathrm{kg} / \mathrm{m}^{2}\right)$ was calculated, 3) WC $(\mathrm{cm})$, measured mid-way between the lateral lower ribs and the iliac crest, using tape measure, and 4) RPG (mg/dl or simply mg\%), by fingertip pinprick method (using Accu-Check ${ }^{\circledR}$ glucometer system from Roche, manufacturer SKU 04528280001, ADM ID: 3231). The cutoff for considering prediabetes in this screening was a "RPG level". as described by $A D A \geq 200 \mathrm{mg} / \mathrm{dl}$ (=11.1 mmol/l) with or without symptoms of diabetes, and without regard to time of last meal [28]. (Also checked was BP; however detailed corresponding data is out of the scope of this work). Patients with suspected prediabetes, (uncontrolled DM, or any other health problem), were transferred to the family medicine outpatient services in AFHWD for confirmatory diagnosis and further management.

Collected data are meant to address important demographic, physiological, and clinical information needed to build up rich database for understanding the prevalent epidemiologic profile of our study population. Important study variables included: 1) age, as an interval ratio scale (IRS), 2) annual income (ordinal) in Saudi Riyal ( $S R=\$ 0.27: \leq 10,000-20,000 ;>20,000-<30,000, \geq 30,000) ; 3$ ) BMI $\left(\mathrm{kg} / \mathrm{m}^{2}\right)$ (IRS; also ordinal as underweight $<20$, normal weight $20-24.9$, overweight 25 - 29.9, stage-1 obesity 30 - 34.9, stage-2 obesity 35 - 39.9, morbid obesity $\geq 40$ ) [33] [34]; 4) participation in any PA or exercise other than the regular job at least once during the last month (yes/no); 5) perceived health status (ordinal: excellent, very good, good, fair, poor); 6) ever diagnosed with HTN (yes/no); 7) ever diagnosed with diabetes (yes/no); and 8) WC (cm) (IRS; but often handled as dichotomous $<102 \mathrm{~cm}$ or $>102 \mathrm{~cm}$ ). (Selected correlates of the study's interest would only be analyzed; the remaining data could be used in fu- 
ture lifestyle studies to evaluate the prevalence of other chronic diseases pursuant to these data).

Statistical analysis plan: The statistical analysis approach principally encompassed descriptive statistics and inferential statistics. The latter may be envisioned from the angle of the effect of hypothesized demographical and physiological risks on RPG as an IRS, as a whole (mean or rank) and their specific effects on the development of prediabetes/diabetes (see inferential statistics below). Nomino-ordinal data, e.g., income or WC groups, would be summarized in tables as count (\%). Also IRS data, e.g., age and systolic BP (SBP) would be summarized as mean \pm standard deviation $(\mathrm{SD})$, or median and interquartile range (IQR), where appropriate, (based on normality distribution, which in turn could be assessed by one-sample Kolmogorov-Smirnov [K-S] test); and range (minimum-maximum). Based on the outcome variable nature, the analytical statistical plan was laid as follows: the outcome variable was set in two forms, a quantitative form which is RPG as an IRS, and a qualitative form as dichotomous RPG $<200 \mathrm{mg} \%$ and RPG $\geq 200 \mathrm{mg} \%$. The quantitative form would be considered an intermediate outcome (dependent) variable, while the qualitative form represents the study's final dependent variable. In intermediate-variable form analysis stage, we were interested in examining the effect of hypothesized risk factors (age, BMI, income, SBP) on RPG level as a whole; not necessarily the development of diabetes/DM. That selected correlates, but income, were reported first-hand IRS in proforma, the correlation between these variables and RPG could first be attempted. (NB. Spearman's correlation would be calculated, all the way, since some of those IRS variables might have fulfilled the normality assumption and others might have been skewed). At the same time, the effect of these correlates on the variability in the level of RPG (as IRS) can be attempted, using statistical parametric techniques (PMTs) or non-PMTs, where appropriate. For example, $t$-test could be used to compare the mean difference in RPG levels among age groups or among WC groups, assuming normality distribution; otherwise, NPMT alternative Mann-Whitney $U$ test would be more appropriate. Likewise, the mean differences in RPG in one of the risk variable which has three or more levels, e.g., income and BMI, could be analyzed using analysis of variance (ANOVA) test, or NPMT alternative Kruskal-Wallis test, where appropriate (based on normality/skewedness assumption).

In the second phase of analysis, we would want to examine the effect of the risk factors on RPG as a frank diabetes/prediabetes disease state, (i.e., categorical variable), in which case cross-tabulation, as in chi-square test (or Fisher's exact test, where appropriate) would be most optimum. The outcome variable nature and design as in above gives this research the privilege of early detection of risks related with the tendency for blood glucose elevation among our study population and those risks could be dealt with, allowing ample downtime until overt diabetes states are put in place. The SPSS software for Microsoft-version-20 was used for statistical analyses. Our level for tolerating alpha error was $\alpha=0.05$; results with p-values $<0.05$ were deemed "statistically significant". 


\section{Results}

In Table 1(a), 531 servicemen turned in valid questionnaire responses; their median age was $33.7 \mathrm{y}$ (IQR 11.9). The most frequently reported income category $(66.3 \%)$ was $<$ SR10,000 - 20,000 $(\mathrm{n}=352)$. Most recruits $(81.8 \%, \mathrm{n}=431)$ were married. The participants' BMI averaged $27.6 \pm 5.4 \mathrm{Kg} / \mathrm{m}^{2}$, which falls within overweight range $\left(25-<30 \mathrm{Kg} / \mathrm{m}^{2}\right.$ ), and had a range of $38.4 \mathrm{Kg} / \mathrm{m}^{2}$ (minimum 15, maximum 53.4) (Table 1(b)). Categorized by BMI, it was found that almost

Table 1. (a) Distribution of participants' demographic criteria $(n=531)^{\star}$. (b) Distribution of participants' physiological criteria $(n=531)$.

(a)

\begin{tabular}{ccccc}
\hline & Characteristic & $\mathrm{n}$ & $\%$ & Notes \\
\hline \multirow{2}{*}{ Age (y) } & Median (IQR): $33.7(11.9)$ & & & Skewed \\
& Range: $20-53$ & ----- & ----- & $($ K-S: $\mathrm{Z}=2.1, \mathrm{p}=0.01)$ \\
Income level (SR) & $>10,000-<20,000$ & 352 & 66.3 & \\
& $>20,000-<30,000$ & 167 & 16.7 & \\
Marital status & $\geq 30,000$ & 12 & 2.3 & \\
& Single & 81 & 15.2 & Missing 19
\end{tabular}

${ }^{*}$ Rank: 504 (95\%) recruit: 462 (87\%) private, 42 (8\%) commissioned officer, 21 (4\%) officer. Missing: 6 (1.1\%).

(b)

\begin{tabular}{|c|c|c|c|c|}
\hline & Characteristic & $\mathrm{n}$ & $\%$ & Notes \\
\hline \multirow{8}{*}{$\begin{array}{c}\text { BMI } \\
\left(\mathrm{Kg} / \mathrm{m}^{2}\right)\end{array}$} & Mean \pm SD: $27.6 \pm 5.4$ & ------- & -----o- & \multirow{8}{*}{$\begin{array}{c}\text { Missing } 12 \\
\text { Normal distribution } \\
(K-S: Z=1.0, p=0.27)\end{array}$} \\
\hline & Range: 38.4 (15 - 53.4) & -------- & ------- & \\
\hline & $<20$ ) (underweight) & 33 & 6.3 & \\
\hline & $20-<25$ (normal) & 143 & 27.0 & \\
\hline & $25-<30$ (overweight) & 185 & 34.7 & \\
\hline & $30-<35$ (obesity-1) & 119 & 22.4 & \\
\hline & $35-<40$ (obesity-2) & 28 & 5.4 & \\
\hline & $\geq 40$ (morbid obesity) & 11 & 2.1 & \\
\hline \multirow{4}{*}{$\mathrm{WC}(\mathrm{cm})$} & Mean \pm SD: $94.7 \pm 13.3$ & ------- & ------- & \multirow{4}{*}{$\begin{array}{c}\text { Missing } 14 \\
\text { Normal distribution } \\
(K-S: Z=1.04, p=0.23)\end{array}$} \\
\hline & Range: $82(62$ - 144) & --.--- & ------- & \\
\hline & $<102$ & 369 & 69.5 & \\
\hline & $\geq 102$ & 148 & 27.9 & \\
\hline \multirow{3}{*}{ Smoking } & Current smoker & 83 & 15.6 & \multirow{3}{*}{ Missing 53} \\
\hline & Nonsmoker (never + quit) & $395(363+32)$ & 74.4 & \\
\hline & Mean duration \pm SD $(y)$ & $11.6+4.5$ & $(68.4+6.0)$ & \\
\hline \multirow{6}{*}{ SBP (mmHg) } & Median \& (IQR): 120 (20) & ------ & ------ & \multirow{6}{*}{$\begin{array}{l}\text { Missing } 15 \\
\text { Skewed } \\
Z=3.6, p<0.0001) \\
\text { Pre-HTN } \\
\text { Uncontrolled }\end{array}$} \\
\hline & Range: 90 - 188 & -------- & -------- & \\
\hline & $<140-$ No H/O HTN & 396 & 74.6 & \\
\hline & $<140-\mathrm{H} / \mathrm{O} \mathrm{HTN}$ & 57 & 10.7 & \\
\hline & $\geq 140-$ No H/O HTN & 42 & 8.0 & \\
\hline & $\geq 140-\mathrm{H} / \mathrm{O} \mathrm{HTN}$ & 21 & 4.0 & \\
\hline \multirow{6}{*}{$\begin{array}{l}\text { RPG level } \\
(\mathrm{mg} / \mathrm{dl})\end{array}$} & Median \& (IQR): 106 (21) & ------ & ------- & \multirow{6}{*}{$\begin{array}{c}\text { Missing } 24 \\
\text { Skewed } \\
(K-S: Z=4.6, p<0.0001) \\
\text { Prediabetes } \\
\text { Uncontrolled }\end{array}$} \\
\hline & Range: 70 - 429 & -------- & -------- & \\
\hline & $<200$ No H/O DM & 452 & 85.1 & \\
\hline & $<200-\mathrm{H} / \mathrm{O} \mathrm{DM}$ & 26 & 4.9 & \\
\hline & $\geq 200-$ No H/O DM & 6 & 1.3 & \\
\hline & $\geq 200-\mathrm{H} / \mathrm{O} \mathrm{DM}$ & 23 & 4.3 & \\
\hline
\end{tabular}


two-thirds $(64.6 \% ; n=343)$ were overweight-up to morbidly obese: $185(34.7 \%)$ overweight, 119 (22.4\%) first degree obesity, 28 (5.4\%) second-degree obesity, and $11(2.1 \%)$ morbid obesity. From the central obesity standpoint, the mean WC of recruits was $94.7 \pm 13.3 \mathrm{~cm}$, range $82(62-144)$. Less than one-third (27.9\%) of recruits had WC $\geq 102 \mathrm{~cm}$. The participants had a median RPG level $106 \mathrm{mg} / \mathrm{dl}(\mathrm{IQR} 21)$; and most recruits $(85.1 \%$; $\mathrm{n}=452)$ had RPG below prediabetes/DM level.

Otherwise, $6(1.3 \%)$ participants who had no history of DM and who were not aware of their blood glucose status had RPG $\geq 200 \mathrm{mg} / \mathrm{dl}$, i.e., "prediabetes". A higher proportion $(4.3 \% ; n=23)$ were known diabetics but sustain abnormally high RPG levels. i.e., "uncontrolled", and another $4.9 \%(\mathrm{n}=26)$ were known diabetics but sustained RPG $<200 \mathrm{mg}$ (“controlled"). The median SBP of recruits was $120 \mathrm{mmHg}$ (IQR 10). Most (74.4\%; $\mathrm{n}=395)$ recruits were non-smokers (Table 1(b)).

As per the analysis plan, Table 2 exhibits the relationship between the hypothesized correlates reported IRS first-hand and RPG level-IRS; all had rather weak, yet significant correlation with RPG; least was income $[r h o(\mathrm{df} 503)=0.118]$, highest WC $[r h o(\operatorname{df} 516)=0.293](\mathrm{p}<0.001$ all $)$.

A strong correlation between BMI and WC was observed [rho(df 518) = 0.873, $\mathrm{p}<0.0001$ ] (Table 2). Importantly, age was strongly correlated with all the risks, including WC, BMI, and SBP. In the same round of statistics, the differences in the levels of RPG among the selected risk categories were calculated (Table 3). All analyses were found statistically significant. For instance, the difference in RPG levels between BMI subcategories were significant $[H(5)=59.6$, $\mathrm{p}<0.0001$ ]; thereby, BMI influences variability in RPG levels in the study group, so that the higher the age the higher the RPG. Both age and waist circumference also significantly influenced the variability in the calculated RPG levels [ $U=$ 19,697.0, $\mathrm{p}<0.001 ; U=25,670.5, \mathrm{p}<0.0001$, respectively]. Income, too, had a significant influence on RPG variation $[H(2)=8.8]$. Although the relationship

Table 2. The relationship between RPG and hypothesized risks: Correlation.

\begin{tabular}{|c|c|c|c|c|c|}
\hline & & RPG & SBP & BMI & WC \\
\hline & Correlation coefficient & 0.226 & 0.256 & 0.306 & 0.374 \\
\hline \multirow[t]{3}{*}{ Age $(y)$} & Sig. (2-tailed) & $<0.0001$ & $<0.0001$ & $<0.0001$ & $<0.0001$ \\
\hline & $n$ & 518 & 519 & 520 & 510 \\
\hline & Correlation coefficient & 0.241 & ----- & 0.370 & 0.349 \\
\hline \multirow[t]{3}{*}{$\mathrm{SBP}(\mathrm{mmHg})$} & Sig. (2-tailed) & $<0.001$ & ------ & $<0.0001$ & $<0.0001$ \\
\hline & $n$ & 528 & ----- & 530 & 519 \\
\hline & Correlation coefficient & 0.253 & ----- & ----- & 0.873 \\
\hline \multirow[t]{3}{*}{$\mathrm{BMI}\left(\mathrm{kg} / \mathrm{m}^{2}\right)$} & Sig. (2-tailed) & 0.0001 & ----- & ----- & $<0.0001$ \\
\hline & $n$ & 529 & ----- & ----- & 520 \\
\hline & Correlation coefficient & 0.293 & ----- & ----- & ------ \\
\hline \multirow[t]{2}{*}{$\mathrm{WC}(\mathrm{cm})$} & Sig. (2-tailed) & $<0.0001$ & ----- & ----- & ----- \\
\hline & $n$ & 518 & ----- & ----- & ----- \\
\hline
\end{tabular}


between BMI categorized and RPG was not straight-line positively proportionate throughout the comparisons, the highest BMI $\left(\geq 40 \mathrm{Kg} / \mathrm{m}^{2}\right)$ had the maximum influence on RPG ranking (mean rank 351.41). Similar fluctuation in the relationship between income and RPG was observed; however low and mid-level income (SR $<10,000-20,000$ and $>20,000-<30,000$ ) were associated with relatively higher RPG levels than highest income (SR $(\geq 30,000)$ category (mean rank 239.7, 280.5, and 236.3), respectively). Importantly, those who were reportedly diabetic in the questionnaire significantly had higher RPG than non-diabetic counterparts [ $U=3515, \mathrm{p}<0.0001]$.

Table 4 shows the concordance between the RPG findings and the participants' awareness of their blood glucose condition, as reported in their response

Table 3. Distribution of RPG level (mean or rank) by age, BMI, WC, and DM.

\begin{tabular}{|c|c|c|c|c|c|}
\hline \multicolumn{2}{|r|}{ Category } & $n$ & $\mathrm{PG}(\mathrm{mg} / \mathrm{dl})^{*}$ & Test statistic & p-value \\
\hline \multirow{2}{*}{ Age $(y)^{* *}$} & $<40$ & 390 & 246.01 & \multirow{2}{*}{$U=19697.0$} & \multirow{2}{*}{$<0.0001$} \\
\hline & $\geq 40$ & 128 & 300.6 & & \\
\hline \multicolumn{2}{|r|}{ Total } & 518 & & \multirow{4}{*}{$H(2)=8.8$} & \multirow{4}{*}{0.012} \\
\hline \multirow{3}{*}{ Income $(\mathrm{SR})^{* *}$} & $<10,000-20,000$ & 237 & 239.7 & & \\
\hline & $>20,000-<30,000$ & 166 & 280.5 & & \\
\hline & $\geq 30,000$ & 12 & 236.3 & & \\
\hline \multirow{7}{*}{$\mathrm{BMI}\left(\mathrm{Kg} / \mathrm{m}^{2}\right)^{\dagger}$} & Total & 505 & & \multirow{7}{*}{$H(5)=59.6$} & \multirow{7}{*}{$<0.000$} \\
\hline & $<20$ & 33 & 236.76 & & \\
\hline & $20-<25$ & 146 & 204.99 & & \\
\hline & $25-<30$ & 188 & 277.14 & & \\
\hline & $30-<35$ & 122 & 308.28 & & \\
\hline & $35-<40$ & 28 & 297.73 & & \\
\hline & $\geq 40$ & 11 & 351.41 & & \\
\hline \multicolumn{2}{|r|}{ Total } & 528 & & & \\
\hline \multirow{2}{*}{$\mathrm{WC}(\mathrm{cm})^{* *}$} & $<102$ & 288 & 223.6 & \multirow{2}{*}{$U=25,670.5$} & \multirow{2}{*}{$<0.0001$} \\
\hline & $\geq 102$ & 127 & 288.9 & & \\
\hline \multirow{3}{*}{ History of $\mathrm{DM}^{* *}$} & Total & 515 & & \multirow{4}{*}{$U=3515.0$} & \multirow{4}{*}{$<0.000$} \\
\hline & Negative & 458 & 223.2 & & \\
\hline & Positive & 49 & 411.3 & & \\
\hline \multicolumn{2}{|r|}{ Total } & 507 & & & \\
\hline
\end{tabular}

${ }^{\star}$ Mean/rank. ${ }^{*}$ Mann Whitney test. ${ }^{\dagger}$ Kruskal-Wallis test.

Table 4. RPG screening results for DM-response groups: Cross-tabulation.

\begin{tabular}{|c|c|c|c|c|c|c|c|c|}
\hline \multirow{3}{*}{ Category } & \multicolumn{6}{|c|}{ Diabetes mellitus awareness status } & \multirow{3}{*}{ Test statistic } & \multirow{3}{*}{ p-value } \\
\hline & \multicolumn{2}{|c|}{ Diagnosed $^{*}$} & \multicolumn{2}{|c|}{ Undiagnosed } & \multicolumn{2}{|c|}{ Total } & & \\
\hline & $\mathrm{n}$ & $\%$ & $\mathrm{n}$ & $\%$ & $\mathrm{n}$ & $\%$ & & \\
\hline $\mathrm{RPG} \geq 200 \mathrm{mg} \%$ & $23^{\dagger}$ & 4.3 & 6 & 1.3 & 29 & 5.6 & & \\
\hline $\mathrm{RPG}<200 \mathrm{mg} \%$ & $26^{1}$ & 4.9 & 452 & 85.1 & 458 & 90 & $\chi^{2}(1)=68.2$ & $<0.0001$ \\
\hline Total & $49^{\ddagger}$ & 9.2 & 458 & 86.4 & 507 & $95.7^{\star \star}$ & & \\
\hline
\end{tabular}

*\% Diagnosed: ${ }^{\dagger} 47 \% ;{ }^{1} 53 \% ;{ }^{\dagger} 12.3 \%$. ${ }^{* *}$ Missing $24(4.4 \%)$. 
to the respective questionnaire items. Forty-nine subjects (9.2\%) were previously diagnosed diabetics ("aware") of their BG condition, 26 (4.9\%) of whom have RPG $<200 \mathrm{mg}$ (controlled), and $4.9 \%$ have RPG $\geq 200 \mathrm{mg}$ (uncontrolled). On the other hand, 6 (1.3\%) of subjects had RPG $\geq 200 \mathrm{mg}$ and they were unaware of their glycemic condition (prediabetes) (can also be called "undiagnosed" or "newly diagnosed") $\left[\chi^{2}(1)=68.2, \mathrm{p}<0.0001\right]$. Overall, the diabetes/prediabetes group totaled $55(10.5 \%)$ subjects, including 23/55 (47\%) aware and uncontrolled (RPG $\geq 200 \mathrm{mg}$ ), 26/55 (53\%) have RPG <200 mg (controlled), and 6/55 (12.3\%) newly diagnosed (prediabetes) (Table 4, footnote).

In the second phase of analysis, the prevalence of the ultimate research outcome, which is prediabetes/diabetes, among the study population was examined. The association between study correlates and the RPG-categorized $<200 \mathrm{mg} / \mathrm{dl}$ and $\mathrm{RPG} \geq 200 \mathrm{mg} / \mathrm{dl}$ was analyzed. In Table 5, age, income, and SBP were significantly related to the development of prediabetes/diabetes; BMI was not. For instance, recruits 40 or older were almost three-times prone to developing RPG $\geq 200$ $\mathrm{mg} / \mathrm{dl}$ than younger peers $(3.6 \%, \mathrm{n}=19$ vs. $1.9 \%, \mathrm{n}=10),\left[\chi^{2}(\mathrm{df} 1)=27.5, \mathrm{p}<\right.$ 0.0001]. Also lower income recruits were more likely to reporting RPG $\geq 200$ $\mathrm{mg} / \mathrm{dl}$ levels than higher income peers $(2.3 \%, \mathrm{n}=12,2.8 \%, \mathrm{n}=15$, and $0.2 \%, \mathrm{n}=$ 1 , respectively). The tendency for recording high BMI levels ( $>25$ and $\geq 40 \mathrm{~kg} / \mathrm{m}^{2}$ among those with reported history of DM was higher than with recording normal

Table 5. Influence of the hypothesized risks on the development of overt prediabetes/DM disease conditions among the study group: Cross-tabulation.

\begin{tabular}{|c|c|c|c|c|c|c|}
\hline \multirow{2}{*}{ Category } & & \multicolumn{3}{|c|}{ RBG Category } & \multirow{2}{*}{ Test statistic } & \multirow{2}{*}{$\mathrm{p}$-value } \\
\hline & & $<200 \mathrm{mg} / \mathrm{dl} \mathrm{n}(\%)$ & $\geq 200$ mg/dl n (\%) & Total & & \\
\hline \multirow{3}{*}{ Age (y) (Missing 23) } & $<40$ & $380(71.6)$ & $10(1.9)$ & $390(73.5)$ & \multirow{3}{*}{$\chi^{2}(\mathrm{df} 1)=27.5$} & \multirow{3}{*}{$<0.0001$} \\
\hline & $\geq 40$ & $109(20.5)$ & $19(3.6)$ & $128(24.1)$ & & \\
\hline & Total & $489(92.1)$ & $29(5.5)$ & $518(97.6)$ & & \\
\hline \multirow{3}{*}{ Income (SR) (Missing 26) } & $<10,000-20,000$ & $315(59.3)$ & $12(2.3)$ & $327(61.6)$ & \multirow{3}{*}{ Fisher's exact $=6.5$} & \multirow{3}{*}{0.036} \\
\hline & $>20,000-<30,000$ & $151(28.4)$ & $15(2.8)$ & $166(31.3)$ & & \\
\hline & $\geq 30,000$ & $11(2.1)$ & $1(0.2)$ & $12(2.3)$ & & \\
\hline \multirow{8}{*}{ BMI $\left(\mathrm{kg} / \mathrm{m}^{2}\right)^{\star}$ (Missing 3$)$} & Total & $477(89.8)$ & $28(5.3)$ & $505(95.1)$ & \multirow{7}{*}{ Fisher's exact $=7.6$} & \multirow{7}{*}{0.131} \\
\hline & $<20$ & $32(6.0)$ & $1(0.2)$ & $33(6.2)$ & & \\
\hline & $20-<25$ & $143(26.9)$ & $3(0.6)$ & $146(27.5)$ & & \\
\hline & $25<30$ & $174(32.7)$ & $14(2.6)$ & $188(35.3)$ & & \\
\hline & $30<35$ & $113(21.3)$ & $9(1.7)$ & $122(22.9)$ & & \\
\hline & $35<40$ & $25(4.7)$ & $3(0.6)$ & $28(5.3)$ & & \\
\hline & $\geq 40$ & $11(2.1)$ & $0(0.0)$ & $11(2.1)$ & & \\
\hline & Total & $498(94.3)$ & $30(5.7)$ & $528(99.4)$ & \multirow{4}{*}{ Fisher's exact $=15.8$} & \multirow{4}{*}{$<0.0001$} \\
\hline \multirow{3}{*}{ SBP (mmHg) (Missing 3) } & $<140$ & $448(84.4)$ & $19(3.6)$ & $467(88.0)$ & & \\
\hline & $\geq 140$ & $51(9.6)$ & $10(1.9)$ & $61(11.5)$ & & \\
\hline & Total & $499(94.5)$ & $29(5.5)$ & $528(99.3)$ & & \\
\hline
\end{tabular}

${ }^{*}$ Waist circumference $(\mathrm{WC})$ was not significantly associated with RPG categorization $\left[\chi^{2}(\mathrm{df} 1) 2.04, \mathrm{p}=0.15\right]$. Known diabetics: associated with BMI $>25$ \& $\geq 40$ more frequently than $\mathrm{BMI}<25 \mathrm{~kg} / \mathrm{m}^{2}(46 \mathrm{v} .5)\left[\chi^{2}(5) 18.8, \mathrm{p}<0001\right]$. 
BMI levels $[46(87 \%)$ vs. $5(0.9)]\left[\chi^{2}(5)=18.8, \mathrm{p}<0.0001\right]$ (Table 4 footnotes). Participants in the lower SBP category $(<140 \mathrm{mmHg})$ tended to record significantly higher frequency of RPG $\geq 200 \mathrm{mg} / \mathrm{dl}$ than those who have SBP $\geq 140$ $\operatorname{mmHg}(3.6, \mathrm{n}=19$ vs. $1.9, \mathrm{n}=10)$ [Fisher's exact $=15.8, \mathrm{p}<0.0001$ ] (Table 5).

\section{Discussion}

The current study is part of a multiphase screening plan to determine important chronic health problems and risks among servicemen in WD, central KSA. The principal research question was centered on identifying whether the glycemic status of recruits meets acceptable health standards at any times during the course of their mission. Thereby, the study population was cross-sectioned to get a snapshot at random, and hence delineate the confounding effect of time and any planned arrangements on the ultimate glycemic picture strove. And that is why we were inclined to adopting RPG as an appropriate measure to achieve research goal. The simplicity, minimal invasiveness, low cost, and timesaving RPG measurement allows through pinprick technique, all encouraged exercising this opportunity with confidence. In experiment, we advocated the internationally accepted standard set by ADA for RPG utilization, i.e., cutoff for considering prediabetes of RPG $\geq 200 \mathrm{mg} / \mathrm{dl}(11.1 \mathrm{mmol} / \mathrm{l})$ (regardless the presence of DM symptoms time of last meal) [28]. In literature, studies were conducted to determine the prevalence of diabetes mellitus, its associated risks in the Saudi populations [19] [35]. Yet, limited surveys were done in the military setting, and most of which were either in the perioperative or surgical settings [36] [37] [38]. However, a study by Afifi et al. (2015) [39] was conducted to analyze correlates of diabetes and prediabetes among recruits in Taif military zone, west Saudi Arabia was retrieved.

Body weight, mass, size risk measures and glycemic state: In practice, WC has been widely used to endorse the presence of "central obesity", which is a pivotal factor contributing to insulin resistance, due to the ability to generate diabetogenic substances [9]. Yes, BMI and WC are highly correlated, and hence unlikely to disagree in reflecting obesity status [8]; however, in some circumstances where obesity assessed by BMI may be rather masked, e.g., by excessive height in taller persons, both measures may be used to neutralize the effect of any interfering confounding. Different cut-off points for obesity, ranging from $78 \mathrm{~cm}$, as in assessing some male Asian populations with one or more cardiovascular risk factors and for identifying those with a BMI above normal [40] to $102 \mathrm{~cm}$, which is the generally international cutoff for male obesity (and $88 \mathrm{~cm}$ for obesity in females), have been in use, based on ethnicity, risk profile, anthropometric and demographic traits, as well as the prevailing dietary behavior. For instance, $102 \mathrm{~cm}$ is considered an obesity limit in MENA (Middle East and North African) region [41] while lower cutoff ( 94 - 100 for men and 80 - 88 for women) [42] are often adopted in Europe, and so forth. In the study on metabolic disorders among Swedish population, Wahrenberg et al. [9] deployed both $\mathrm{BMI}$ and WC to measure the relationship between metabolic syndromes and in- 
sulin sensitivity in the studied population. Wahrenberg et al. used $100 \mathrm{~cm}$ (both sexes) as a cutoff of interest, whereas WC could explain more than $50 \%$ of the variability in insulin sensitivity alone. Also, type 2 diabetes may itself cause obesity as an effect of the changes in metabolism attendant on insulin resistance [10]. Due to all those reasons, perhaps it is logic to introduce WC to risk behavior survey measures targeting populations of culture and ethnic origins. In this work, we utilized both BMI and WC in evaluating hyperglycemic risks in the study community. And especially central obesity would be particularly important to explore in order to further assess DM risks in a society such as the Saudi's struggling with weight and diabetes problems presently and probably for years to come. To the best interest of this research, too, a strong correlation between BMI and WC was found, which potentiates any proportional association between body weight or size and hyperglycemic syndromes studied.

The awareness of having diabetes failed to motivate affected subjects to sustain adequate control of blood glucose level. The difference in the frequency of subjects with prediabetes/diabetes, either controlled or uncontrolled and whether they were aware of their BG condition, and peers with RPG $<200 \mathrm{mg} / \mathrm{dl}$ is in favor of the latter. This may be more or less reassuring, especially that the general RPG pattern classifies our participants into the normal physiological BG range (median $106 \mathrm{mg} / \mathrm{dl}$, IQR 21). However, the approximate equality in the frequency of uncontrolled diabetes cases $(4.3 \%, n=23)$ who are aware of their DM condition and those who are rather controlled and also aware they have DM $(4.9 \%, \mathrm{n}=26)$ is rather worrying. Simply this means that the awareness of one's BG condition failed to protect them against hyperglycemia. More seriously would be to envision this failure from the angle of diabetes management policy in place, since diabetic patients could be kept in a rather safe BG window only $50 \%$ of the time. Now, assuming the presence of an adequately planned diabetes control and follow up by the offered health care services, the high RPG pattern found in diabetic recruits could imply an inadequate health behavior or perhaps poor compliance to prescribed treatment protocols, including oral hypoglycemic and other lines of treatment [24]. Other explanations for the discrepancy between adequacy of DM management policy and any unfavorable health outcome can be attempted. For instance, improperly high plasma glucose (IHPG) in diabetics often accompanies comorbid conditions, such as infection, stress or other health challenges. All these scenarios ascertain the need to keep our diabetic group under close surveillance and guidance by an efficient health education plan in order to reduce fluctuation of plasma glucose level; accordingly any advance to the distressing angiopathic complications could be postponed [39]. Adopting an integrated diabetes management strategy which appreciates the role of continuous patient and family education and close follow up bridges the gap between policy and the health outcomes, e.g., in terms of better glycemic control in diabetic patients, body mass and abdominal size, and glucose level monitoring at different age phases of our community.

When we were first hypothesizing for this research, we did not expect to get a 
direct temporal cause-effect relationship between BP as a risk exposure and hyperglycemia as an outcome. However we were willing to understand the presence of a form of correlation between the two conditions. In other words, a temporal relationship where pre-HTN or HTN predisposes DM was not an option. In fact the opposite could have been more of a concern. It is well documented that DM is associated with a variety of small and large blood vessel disease, which plays a role in developing a myriad of body organ pathologies, including nephropathy, retinopathy, CVD and elevated BP. In a study on HTN and type $2 \mathrm{DM}$, tight control of BP significantly reduced risks of deaths and vasculopathic complications related to diabetes [43]. To this end, we may learn from this research through the significant correlation between SBP and RPG that IHPG can be risk for developing pre-HTN/HTN. (Studying the underlying determinants which may influence this relationship is among the current WD community diagnosis project and a study with this focus is underway).

In Osaimi and collaborates (2007) work to determine the prevalence and CVD risks in a suburban community in eastern Riyadh district, KSA, [35] 71/451 $(15.8 \%)$ of those surveyed had type 2 diabetes vs. $10.5 \%$ of subjects in our study. Furthermore, 59/71 (83\%) of east Riyadh diabetic population was previously diagnosed vs. 49/55 (89\%) of our study peers. Among known diabetics, only 17/59 (28.8\%) were controlled vs. $26 / 49$ (53\%) sustaining RPG $<200 \mathrm{mg} \%$ in this research. Lastly, 12 individuals ( $1.7 \%$ of total study population and $10.9 \%$ of all diabetics) in east Riyadh survey were newly diagnosed, compared to 6 (1.3\% of total and $10.9 \%$ of diabetes/prediabetes) newly diagnosed recruits in WD. Moreover, the rate of uncontrolled PG in Osaimi et al. was $42 / 59$ (71.2\%) vs. $23 / 49$ (47\%) in WD. Both rates are undesirable, but the situation in Osaimi et al. population is much direr. Apparently, Osaimi et al. figures reflect a less favorable diabetes picture, in terms of prevalence, control measures, and screening outcome. A multitude of factors could be behind this difference; for instance, using RBG cutoff perhaps permitted a wider glycemic span for our study group and hence a larger number of individuals within this range could be categorized within "normal" PG spectrum. Some may argue that RPG with as "high" as $200 \mathrm{mg} \%$ glucose cutoff compromises test specificity (incurring a higher "false negative" to higher "true positive" result) in favor of magnifying test sensitivity. The debate about the most appropriate tools in diagnosing glycemic levels arises from time to time in the research community. However, most concerned international organizations, such as the WHO, and other reputed professional and regulatory organizations, such as $\mathrm{ADA}$, and peer-reviewed research, ascertain a high level of validity and reliability of RPG with the designated $200 \mathrm{mg} / \mathrm{dl}$ cutoff, as comparable to laboratory glucose measurement [29] [44] [45]. On our part, we still argue that the difference in the two studies may well be due to a genuine difference in the risk-outcome profile of the two populations, e.g., lifestyle, healthcare or preventive service standard, not just the confounding effect of demographic criteria of the two study populations. Instead, rather head-to-head comparison with the study by Afifi et al., 2015 [39] could be attempted, espe- 
cially since both studies share common setting and some objectives. In afifi et al. study, recruits were screened to determine risks and prevalence of prediabetes/ diabetes in Taif, west KSA military suverinity. The authors in Taif screening reported that 28/117 (23.9\%) had diabetic-level RPG, almost triple our rate (10.5\%). Out of those screened hyperglycemic, $60.7 \%$ (17/28) were previously diagnosed, equals up to one and a half times the rate of our study's previously diagnosed diabetic $(49 / 55=89 \%)$. Among the diagnosed in Taif, only $3 / 17(10.7 \%)$ recruits were controlled, compared to $26 / 49$ (53\%) in WD recruits. The rate of newly diagnosed among all diabetics in Taif study mount to $11 / 28$ (39.3\%), almost a quadruple the rate of screening prediabetes in WD military community $(6 / 55=$ $10.9 \%$ all diabetics, and $1.3 \%$ of study population). Obviously, the prevalence of diabetes and related risks and outcome statistics in WD are remarkably lower than those in the western zone study. In the comparison, Taif study recruits median age was 42 y (IQR 5), compared to 33.7 y (IQR 11.9) in ours', since their study tended to include recruits 40 and above. (Those people were not well represented in a preceding risk behavior survey in Taif military district) [29]. Also, the anthropometric criteria in Taif were higher than ours, e.g., mean BMI $30 \pm 13 \mathrm{~cm}$ vs. $27.6 \pm 5.4$; and WC $100.2 \pm 10 \mathrm{~cm}$ vs. only $94.7 \pm 13.3 \mathrm{~cm}$, respectively in WD. Ultimately, Taif recruits bear greater diabetes risks load; however such higher glycemic risk indices cannot be attributed to age alone. Just as those in the Riyadh study comparison, [35] factors specific to WD military community, e.g., lifestyle, could play an important role in assuring better environment for a different diabetes outcomes in these communities. Merit of such outcomes should be motive to explore the positive side of WD recruits' epidemiology and the preventive and therapeutic health service package offered, to maximize; and further analyze the negative sides and then develop strategies to bridge the diagnosed gap.

Risk factors and the study population's glycemic profile: Regardless whether there was a high tendency for IHPG, both the nature of the disease in question (a disease of complications) and the surveyed population (men in uniform) are so sensitive to the degree that even a mild deviation from the most desirable health status could give reason for concern. The WC profile $(94.7 \pm 13.3 \mathrm{~cm})$ in this work could be a strong factor for non-insulin resistance [9]. However, WC is not the only factor to impact RPG found. For instance, the correlation between our cohort's WC and age is comparable to the finding from a study on DM in 2004 on Saudis [19], which showed that age was risk to prediabetes. In turn, prediabetes could progress to DM, probably in as high as $50 \%$ of cases, if lifestyle changes were not made [46]. Ever since, an escalating diabetes problem with a concurrent comorbidity profile in Saudi Arabia was reported. In a large-sample screening to follow up some chronic diseases, Al-Daghri et al. (2011) reported that the prevalence of type 2 diabetes in Saudi accounted $23.1 \%$ of the general population, and specifically $34.7 \%$ among males, [47] compared with $10.5 \%$ in our study $[4.3 \%(n=23)$ uncontrolled, $4.9 \%$ controlled $(n=26), 1.3 \%(n=6)$ newly diagnosed]. The study also reveals that $25.1 \%$ of the population were ob- 
ese, compared to $29.9 \%(\mathrm{n}=158)(\mathrm{BMI} \geq 30)$. In contrast to ours, Al-Daghri et al., the cohort were only selected from urban Riyadh to reflect the epidemiologic pattern specific to civil life. Our study's community, however, is mere servicemen; perhaps a factor that warrants an utmost degree of maintained fitness, e.g., through better control of the glycemic status, compared to Al-Daghri et al. citizens. Lower prevalence rates (18.2\%) of screened with diabetes (both sexes) in the eastern coastal province of Saudi Arabia were reported [48]; almost half of Al-Daghri et al. and double of ours. (Unsurprisingly, the two studies used the same data system "Biomarkers Screening in Riyadh Program").

Although it is now well documented that the prevalence of DM in KSA is among the highest worldwide and its yield of general screening has almost always been high, the partial extension of this phenomenon to involve the military community warrants intervention. Particularly an equivalent prevalence of two diagnosed diabetic varieties, uncontrolled and controlled is a true concern, which entails comprehensive reviews of diabetes control policy, engaging both the healthcare providing and follow up sector's performance, and most importantly patients' responses and behavior. An organized effort in parallel with proceeding with the screening plan of WDMH is needed to reduce relevant obesity and lifestyle risk in order to maintain and promote health of the served community. For instance, the use of lower cutoff for weight and abdominal size, especially in risk groups enhances specificity of the screening and hence assures earlier intervention for high risk individuals. Hypothesizing about reasons such as those related to age and socioeconomic status for developing diabetes based on physiology, genetic makeup, regulation and expression of cells and tissues under those conditions, this set of risk-outcome relationship stands as basis to tackle the issue in the future. An insufficient awareness and knowledge about diabetes and related risks; how to avoid and the early symptoms when medical care must be sought; would rather be continually evaluated. Should diabetes "neglect" become a trend; the frequency of secondary complications would be on the rise. The duration of diabetes, detailed management information and tracking BG behavior over DM disease course, are all seat for future research.

\section{References}

[1] International Diabetes Federation (IDF) (2016) Diabetes: A Global Emergency. The Global Picture. 7th Edition, 51. http://www.diabetesatlas.org/

[2] Shi, Y. and Hu, F.B. (2014) The Global Implications of Diabetes and Cancer. The Lancet, 383, 1947-1948. https://doi.org/10.1016/S0140-6736(14)60886-2

[3] Kumar, V., Fausto, N., Abbas, A.K., Cotran, R.S. and Robbins, S.L. (2005) Robbins and Cotran Pathologic Basis of Disease. 7th Edition, Saunders, Philadelphia, 11941195.

[4] Risérus, U., Willett, W.C. and Hu, F.B. (2009) Dietary Fats and Prevention of Type 2 Diabetes. Progress in Lipid Research, 48, 44-51. https://doi.org/10.1016/j.plipres.2008.10.002

[5] Mozaffarian, D., Kamineni, A., Carnethon, M., Djoussé, L., Mukamal, K.J. and Siscovic, D. (2009) Lifestyle Risk Factors and New-Onset Diabetes Mellitus in Older 
Adults: The Cardiovascular Health Study. Archives of Internal Medicine, 169, 798807. https://doi.org/10.1001/archinternmed.2009.21

[6] Centers for Disease Control and Prevention (CDC) (2004) Prevalence of Overweight and Obesity among Adults with Diagnosed Diabetes, United States, 19881994 and 1999-2002. Morbidity and Mortality Weekly Report, 53, 1066-1068.

[7] Wee, C.C., Hamel, M.B., Huang, A., Davis, R.B., Mittlemn, M.A. and McCarthy, E.P. (2008) Obesity and Undiagnosed Diabetes in the U.S. Diabetes Care, 31, 1813 1815. https://doi.org/10.2337/dc07-1867

[8] Vazquez, G., Duval, S., Jacobs, D.R. and Silventoinen, K. (2007) Comparison of Body Mass Index, Waist Circumference, and Waist/Hip Ratio in Predicting Incident Diabetes: A Meta-Analysis. Epidemiologic Reviews, 29, 115-128. https://doi.org/10.1093/epirev/mxm008

[9] Wahrenberg, H., Hertel, K., Leijonhufvud, B.M., Persson, L.G. and Toft, A.P. (2005) Use of Waist Circumference to Predict Insulin Resistance: Retrospective Study. BMJ, 330, 1363-1364. http://www.ncbi.nlm.nih.gov/pmc/articles/PMC558285 https://doi.org/10.1136/bmj.38429.473310.AE

[10] Camastra, S., Bonora, E., Del Prato, S., Rett, K., Weck, M. and Ferrannini, E. (1999) Effect of Obesity and Insulin Resistance on Resting and Glucose-Induced Thermogenesis in Man. EGIR (European Group for the Study of Insulin Resistance). International Journal of Obesity and Related Metabolic Disorders, 23, 1307-1313. https://doi.org/10.1038/sj.ijo.0801072

[11] James, W.D., Berger, T. and Elston, D. (2006) Andrews' Diseases of the Skin: Clinical Dermatology. Saunders Elsevier, Philadelphia.

[12] Jack, L., Boseman, L. and Vinicor, F. (2004) Aging Americans and Diabetes. A Public Health and Clinical Response. Geriatrics, 59, 14-17.

[13] Hu, F.B. (2003) Sedentary Lifestyle and Risk of Obesity and Type 2 Diabetes. Lipids, 38, 103-108. https://doi.org/10.1007/s11745-003-1038-4

[14] Lang, I.A., Galoway, T.S., Scarlett, A., Henley, W.E., Depledge, M., Wallace, R.B. and Melzer, D. (2008) Association of Urinary Bisphenol A Concentration with Medical Disorders and Laboratory Abnormalities in Adults. JAMA, 300, 1303-1310. https://doi.org/10.1001/jama.300.11.1303

[15] Cotran, R.S., Kumar, V., Collins, T. and Robbins, S.L. (1999) Robbins Pathologic Basis of Disease. 6th Edition, Saunders, Philadelphia, 913-926.

[16] Abate, N. and Chandalia, M. (2003) The Impact of Ethnicity on Type 2 Diabetes. Journal of Diabetes and Its Complications, 17, 39-58. https://doi.org/10.1016/S1056-8727(02)00190-3

[17] Shaw, J.E., Sicree, R.A. and Zimmet, P.Z. (2010) Global Estimates of the Prevalence of Diabetes for 2010 and 2030. Diabetes Research and Clinical Practice, 87, 4-14.

[18] Memish, Z., El Bcheraoui, C., Tuffaha, M., Robinson, M., Daoud, F. and Jaber, S. (2014) Obesity and Associated Factors-Kingdom of Saudi Arabia, 2013. Preventing Chronic Disease, 11, E174. https://doi.org/10.5888/pcd11.140236

[19] Al-Nozha, M.M., Al-Maatouq, M.A., Al-Mazrou, Y.Y., Al-Harthi, S.S., Arafah, M.R., Khalil, M.Z., Khan, N.B., Al-Khadra, A., Al-Marzouki, K., Nouh, M.S., Abdullah, M., Attas, O., Al-Shahid, M.S. and Al-Mobeireek, A. (2004) Diabetes Mellitus in Saudi Arabia. Saudi Medical Journal, 25, 1603-1610.

[20] Alwakeel, J.S., Al-Suwaida, A., Isnani, A.C., Al-Harbi, A. and Alam, A. (2009) Concomitant Macro and Micro-Vascular Complications in Diabetic Nephropathy. Saudi Journal of Kidney Diseases and Transplantation, 20, 402-409.

[21] Akinci, F., Healey, B.J. and Coyne, J.S. (2012) Improving the Health Status of US 
Working Adults with Type 2 Diabetes Mellitus. Disease Management \& Health Outcomes, 11, 489-498. https://doi.org/10.2165/00115677-200311080-00002

[22] Wild, S., Roglic, G., Green, A., Sicree, R. and King, H. (2004) Global Prevalence of Diabetes: Estimates for the Year 2000 and Projections for 2030. Diabetes Care, 27, 1047-1053. https://doi.org/10.2337/diacare.27.5.1047

[23] American Diabetes Association (ADA) (2004) Screening for Type 2 Diabetes. Position Statement. Diabetes Care, 27, s11-s14.

http://care.diabetesjournals.org/content/27/suppl_1/s4.full https://doi.org/10.2337/diacare.27.2007.S11

[24] Waugh, N., Scotland, G., McNamee, P., Gillett, M., Brennan, A., Goyder, E., Williams, R. and John, A. (2007) Screening for Type 2 Diabetes: Literature Review and Economic Modeling. Health Technology Assessment, 11, 1-144.

https://doi.org/10.3310/hta11170

[25] Engelgau, M.M., Narayan, K.M.V. and Herman, W.H. (2000) Screening for Type 2 Diabetes. Diabetes Care, 23, 1563-1580. https://doi.org/10.2337/diacare.23.10.1563

[26] Valdez, R. (2009) Detecting Undiagnosed Type 2 Diabetes: Family History as a Risk Factor and Screening Tool. Journal of Diabetes Science and Technology, 3, 722-726. https://doi.org/10.1177/193229680900300417

[27] U.S. Preventive Services Task Force (2008) Screening: Type 2 Diabetes Mellitus in Adults. http://www.uspreventiveservicestaskforce.org/uspstf/uspsdiab.htm

[28] American Diabetes Association (ADA) (2000) Screening for Type 2 Diabetes. Position Statement. Diabetes Care, 23, S77-S79.

http://care.diabetesjournals.org/content/27/suppl_1/s11.full?maxtoshow=\&HITS=1 0\&hits=10\&RESULTFORMAT $=\&$ fulltext=screening + for+type $+2+$ diabetes \&searchi $\mathrm{d}=1083098689392 \_7996 \&$ stored_search $=\&$ FIRSTINDEX $=0$ \&sortspec $=$ relevance\&jo urnalcode $=$ diacare

[29] Al-Asmary, S.M., Al-Shehri, A.A., Farahat, F.M., Abdel-Fattah, M.M., Al-Shahrani, M.M., Al-Omari, F.K., Al-Otaibi, F.S. and Al-Malki, D.M. (2008) CommunityBased Screening for Pre-Hypertension among Military Active Duty Personnel. Saudi Medical Journal, 29, 1779-1784.

[30] Behavioral Risk Factor Survey Module: Definitions of Survey Measures. Wisconsin Behavioral Risk Factors Survey. http://www.dhs.wisconsin.gov/wish/main/BRFS/definitions.htm

[31] Wildman, R.P., Gu, D., Reynolds, K., Duan, X. and He, J. (2004) Appropriate Body Mass Index and Waist Circumference Cutoffs for Categorization of Overweight and Central Adiposity among Chinese Adults. American Journal of Clinical Nutrition, 80, 1129-1136.

[32] Keys, A., Fidanza, F., Karvonen, M.J., Kimura, N. and Taylor, H.L. (1972) Indices of Relative Weight and Obesity. Journal of Chronic Diseases, 25, 329-343. https://doi.org/10.1016/0021-9681(72)90027-6

[33] World Health Organization (WHO) (2000) Obesity: Preventing and Managing the Global Epidemic. WHO Technical Report Series 894, Geneva.

[34] National Center for Chronic Disease Prevention and Health Promotion (2004) Defining Overweight and Obesity. Overweight and Obesity among Adults. http://www.athealth.com/consumer/disorders/definingobesity.html

[35] Osaimi, S. and AL-Gelban, K.S. (2007) Diabetes Mellitus-Prevalence and Associated Cardiovascular Risk Factors in a Saudi Sub-Urban Community. Biomedical Research, 18, 147-153.

[36] Emam, I.A., Allan, A., Eskander, K.h., Dhanraj, K., Farag, E., El-Kadi, Y., Khalaf, 
W., Riad, S.R. and Somia, R. (2010) Our Experience of Controlling Diabetes in the Peri-Operative Period of Patients Who Underwent Cardiac Surgery. Diabetes Research and Clinical Practice, 88, 242-246.

https://doi.org/10.1016/j.diabres.2010.03.002

[37] Shoaib, K.K., Khan, A.A. and Qadir, A. (2008) Frequency of Diabetes Mellitus, Impaired Oral Glucose Tolerance Test, Hepatitis B Surface Antibody (HCV Ab) in Saudi Population Undergoing Cataract Surgery. Pakistan Journal of Ophthalmology, 24, 12-15.

[38] Onwubalili, J.K. and Obineche, E.N. (1991) High Incidence of Post-Transplant Diabetes Mellitus in a Single-Centre Study. Nephrology Dialysis Transplantation, 7, 346-349.

[39] Afifi, R., Omar, S. and El Raggal, A. (2015) A Community Screening Plan for the Prevalence of Some Chronic Diseases in Specified Adult Populations: Pre-Diabetes and Diabetes Mellitus. International Journal of Diabetes in Developing Countries, 35, 149-156. https://doi.org/10.1007/s13410-013-0189-0

[40] Misra, A., Vikram, N.K., Gupta, R., Pandey, R.M., Wasir, J.S. and Gupta, V.P. (2006) Waist Circumference Cutoff Points and Action Levels for Asian Indians for Identification of Abdominal Obesity. International Journal of Obesity, 30, 106-111. https://doi.org/10.1038/sj.ijo.0803111

[41] International Diabetes Federation (IDF) Middle East and North Africa (2015) Diabetes in Saudi Arabia-2015. http://www.idf.org/membership/mena/saudi-arabia

[42] International Diabetes Federation (IDF) (2006) Abdominal Obesity Measurement Guidelines for Different Ethnic Groups.

http://www.idf.org/webdata/docs/IDF_Meta_def_final.pdf

[43] UK Prospective Diabetes Study Group (1998) Tight Blood Pressure Control and Risk of Macrovascular and Microvascular Complications in Type 2 Diabetes: UKPDS 38. BMJ, 317, 703-713. https://doi.org/10.1136/bmj.317.7160.703

[44] World Health Organization (WHO) (2006) Diabetes Programme. Definition and Diagnosis of Diabetes Mellitus and Intermediate Hyperglycaemia. Report of a WHO/IDF Consultation. http://www.who.int/diabetes/publications/diagnosis_diabetes2006/en/

[45] Nayeri, F., Shariat, M., Mousavi, B.H.M., Dehghan, P. and Ebrahim, B. (2014) Blood Glucose Measurement by Glucometer in Comparison with Standard Method in Diagnosis of Neonatal Hypoglycemia. Acta Medica Iranica, 52, 619-622.

[46] Nichols, G.A., Hillier, T.A. and Brown, J.B. (2007) Progression from Newly Acquired Impaired Fasting Glusose to Type 2 Diabetes. Diabetes Care, 30, 228-233. https://doi.org/10.2337/dc06-1392

[47] Al-Daghri, N.M., Al-Attas, O.S., Alokail, M.S., Alkharfy, K.M., Sabico, S.L.S. and Chrousos, G.P. (2011) Diabetes Mellitus Type 2 and Other Chronic Non-Communicable Diseases in the Central Region, Saudi Arabia (Riyadh Cohort 2): A Decade of an Epidemic. BMC Medicine, 9, 76. https://doi.org/10.1186/1741-7015-9-76

[48] Al-Baghli, N.A., Al-Ghamdi, A.J., Al-Turki, K.A., Al Elq, A.H., El-Zubaier, A.G. and Bahnassy, A. (2010) Prevalence of Diabetes Mellitus and Impaired Fasting Glucose Levels in the Eastern Province of Saudi Arabia: Results of a Screening Campaign. Singapore Medical Journal, 51, 923-930. 
Submit or recommend next manuscript to SCIRP and we will provide best service for you:

Accepting pre-submission inquiries through Email, Facebook, LinkedIn, Twitter, etc. A wide selection of journals (inclusive of 9 subjects, more than 200 journals)

Providing 24-hour high-quality service

User-friendly online submission system

Fair and swift peer-review system

Efficient typesetting and proofreading procedure

Display of the result of downloads and visits, as well as the number of cited articles Maximum dissemination of your research work

Submit your manuscript at: http://papersubmission.scirp.org/

Or contact jdm@scirp.org 